\title{
Integrated approach to training of medical students for chronic care of diabetes - an educational intervention project experience from MIMS, Mandya, Karnataka
}

\author{
Poornima $\mathrm{S}^{1}$, Ramkrishna $\mathrm{S}^{2}$, Shivakumar $\mathrm{KM}^{3}$, \\ ${ }^{1}$ Assistant Professor, Department of Community Medicine, Mandya Institute of Medical Sciences (MIMS), Mandya, \\ Karnataka, India \\ ${ }^{2}$ Assistant Professor, Department of General Medicine, Mandya Institute of Medical Sciences (MIMS), Mandya, Karnataka, \\ India \\ ${ }^{3}$ Professor and Head, Department of General Medicine, Mandya Institute of Medical Sciences (MIMS), Mandya, Karnataka, \\ India
}

\begin{abstract}
Back Ground:

Nearly 51 million Indians are living with diabetes in India. With an estimated three fold rise in the prevalence of diabetes over the next 25 years, it is important that we plan ahead and make strategic changes, embarking seriously on capacity building of medical students for chronic care of diseases like diabetes.

Objective:

To assess the effectiveness of an integrated training workshop for chronic care of diabetes among medical students of MIMS, Mandya.

Methodology:

Three days intensive integrated training workshop was conducted for 30 randomly selected MBBS Phase III - Part I students with must know aspects of Diabetes using the World Health Organization's Integrated Management of Adult and adolescent Illnesses (IMAI) model of chronic care, based on 5A's (Assess, Advice, Agree, Assist and Arrange) and TEAM-P (Triage, Education, Assessment, Management and support for Positive living) approach. Written, structured pre-test, post test and feedback from the students was taken and the observations are being presented in this paper.
\end{abstract}

Results:

There was significant increase in the mean scores from 14.96 (S.D. $=4.66,99 \%$ C.I $=12.62-17.30$ ) to a post test score of 26.76(S.D. $=3.21,99 \%$ C.I $=25.16-28.36)$, $\mathrm{p}<0.00001 .5 \mathrm{~A}$ 's and TEAM $-\mathrm{P}$ approaches were easy to remember and practice.

Conclusion:

An integrated training workshop is effective in increasing the knowledge, understanding and confidence of medical students, and thus molding them in handling the patients of diabetes for continuum of care.

Keywords: Integrated training, Medical students, 5A's, Continuum of Care, Diabetes, Intensive workshop,

\section{BACKGROUND}

Diabetes is a chronic condition that requires continuing medical care and ongoing patient self-management, education and support, in order to prevent and reduce the risk of acute and long-term complications. Care of patients with diabetes requires addressing issues, beyond glycemic control ${ }^{[1]}$. Chronic care in diabetes refers to medical care addressing preexisting or long term illness care, as opposed to acute care which generally concerned with short term or severe illness care of brief duration ${ }^{[2,3]}$.

Nearly 51 million Indians are suffering from diabetes at present.It is estimated that there shall be a 3 fold increase in the burden of diabetes diseases over the next 25 years, as the epidemiologic, socio economic and age structures profile of our country are conducive ${ }^{[1,3]}$. Tackling the epidemic of chronic diseases like diabetes is faced with many challenges ${ }^{[4]}$. With a health system equipped to meet the acute or episodic needs of the patients and the budgetary allocation for health saturating at $5 \%$ of GDP over the last decades, meeting the challenges of the chronic diseases like diabetes may not be possible unless, we plan ahead and make strategic changes ${ }^{[5,6]}$. Embarking seriously on capacity building for chronic care of diseases is the need of the hour. However, extensive research is needed to identify quick, feasible and cost-effective interventions in countries like India ${ }^{[7,8]}$. 


\section{Objective}

To assess the effectiveness of an integrated training workshop for chronic care of diabetes among the medical students of MIMS, Mandya

\section{Methods}

An integrated intensive training workshop on chronic care was organized for the medical students of Mandya Institute of Medical Sciences, Mandya, Karnataka. The workshop was conducted by faculty, trained in chronic care from the department of General Medicine and Community Medicine. Small group teaching learning techniques were used in the workshop.

This activity was a part of pilot educational intervention project titled Continuum of Care for Chronic Diseases, funded by the WHO SEARO India office from July 2011-Dec 2011. The observations pertaining to the chronic care of diabetes are being presented in this paper. The workshop was conducted for MBBS, Phase III - Part I students (2008 MBBS batch). Since the intake of MBBS students at MIMS for this year was 100 and this was an educational intervention program, we decided to have at least $25 \%$ ( 25 out of 100 students) of the total Undergraduate students in the study and control groups respectively. Participation of students in the workshop was on a voluntary basis. 78 students volunteered to participate. Each student was assigned a number and using a random number table 30 students were assigned to participants group and another 30 students assigned as the peer controls.

The chronic care model for diabetes used for the workshop was developed on the samelines as the existing Integrated Management of Adult and Adolescent Illness (IMAI) module of the World Health Organizations. The chronic care model focused on the 5 A's and TEAM-P approach. The 5 A's stand for - Assess, Advise, Agree, Assist and Arrange, TEAM-P stands for Triage, Education, Assessment, Management and support for Positive living.

The contents of the workshop included introduction to principles of chronic care, sequence of care and the must know aspects of chronic care of diabetes. Day-1 of the workshop was to impart the students with knowledge on concepts and sequence of chronic care in diabetes including the must know aspects of diabetes. Day-2 of workshop focused on skill development of students by practice of the chronic care model in the wards. The students practically worked-up different cases of diabetes in pairs and documented the same in their logbooks provided. The students also had demonstration of correct insulin injection techniques, followed by practice of the same on models. Day-3 was discussion of the individual cases and included demonstration of good communication skills by role-plays from faculty and students. The day concluded by students seeking clarification and their experiences in the class room.

The students were subjected to written, structured pre-test and post test evaluation. The feedback from the students was taken. Data was entered into the Microsoft 2007 spreadsheet. Mean, standard deviations and $99 \%$ confidence intervals were computed. Student's unpaired and paired t-test was applied to test for statistical significance.

\section{Results}

Of the 30 study participants, 14 were males, 16 were females. 26 study participants from 2008 regular batch and 4 students were from 2008 odd batch. However, of the 30 student peers as controls, 12 were males and 18 were females.

Table 1: Comparison of the mean pre test scores of the study participants and peer controls

\begin{tabular}{|l|c|c|c|l|}
\hline \multicolumn{5}{|c|}{ Diabetes } \\
\hline Participants & Mean & $\begin{array}{l}\text { Standard } \\
\text { Deviation }\end{array}$ & $\begin{array}{l}\text { 99 \% Confidence } \\
\text { Interval }\end{array}$ & $\begin{array}{l}\text { p } \\
\text { value }\end{array}$ \\
\hline Participants & 14.96 & 4.45 & $12.62-17.30$ & $>0.05$ \\
\hline $\begin{array}{l}\text { Peer } \\
\text { controls }\end{array}$ & 15.76 & 3.18 & $14.16-17.36$ & \\
\hline
\end{tabular}


The mean score of the participants was 14.96 as against 15.76 for the peer controls. The maximum attainable score was 38. Comparing between the two means done by using unpaired students $t$ test did not show statistically significant difference between the participants and peer controls $(\mathrm{p}>0.05)$.

Table 2: Comparison of the mean pretest scores of the Participants with the mean post test scores

\begin{tabular}{|c|c|c|c|c|c|c|c|}
\hline \multicolumn{4}{|l|}{ Pre test } & \multicolumn{3}{|c|}{ Post test } & \multirow[b]{2}{*}{ P- value } \\
\hline & Mean & $\begin{array}{l}\text { Standard } \\
\text { Deviation }\end{array}$ & $\begin{array}{l}99 \% \\
\text { Confidence } \\
\text { Interval }\end{array}$ & Mean & $\begin{array}{l}\text { Standard } \\
\text { Deviation }\end{array}$ & $\begin{array}{l}99 \\
\text { Confidence } \\
\text { Interval }\end{array}$ & \\
\hline Diabetes & 14.96 & 4.66 & $12.62-17.30$ & 26.76 & 3.21 & $25.16-28.36$ & $<0.00001$ \\
\hline
\end{tabular}

The mean post score was 26.76 (maximum attainable score was 38) with a standard deviation of 3.21 and $99 \%$ confidence interval 25.16-28.36 after the intensive training workshop. Paired t-test applied showed a statistically significant increase in the mean scores among the participants following completion of intensive training workshop $(\mathrm{p}<0.00001)$

Students opined that, the 5A's were easy to remember and they benefited maximum in the areas of T - Triage, Eeducation and $\mathrm{S}$ - support for positive living components as these components were not stressed in routine teaching.

Table 3: Participants feedback about the effectiveness of the workshop

\begin{tabular}{|l|c|c|}
\hline \multicolumn{1}{|c|}{ Opinions } & No. of participants & Percentage \\
\hline $\begin{array}{l}\text { Brought about an attitudinal } \\
\text { change towards chronic care }\end{array}$ & 23 & 76.66 \\
\hline Increased Understanding & 22 & 73.33 \\
\hline $\begin{array}{l}\text { Increased confidence in handing } \\
\text { patients with diabetes for chronic } \\
\text { care }\end{array}$ & 28 & 93.33 \\
\hline $\begin{array}{l}\text { 5A's and TEAM-P components } \\
\text { Easy to remember and practice }\end{array}$ & 24 & 80.00 \\
\hline $\begin{array}{l}\text { Should be a part of regular } \\
\text { university curriculum }\end{array}$ & 28 & 93.33 \\
\hline
\end{tabular}

The student feedback revealed that the contents of the workshop was very useful in emphasizing the must know aspects of diabetes. The integration of faculty from various departments helped in experience sharing, bridging the gap between theory and practical. The teaching learning techniques used for the workshop including interactive lecture with power point slides, demonstration and hands on training for skill building, using charts, handouts, log books made learning easy. Case scenarios, case taking, case log books and role plays helped re-enforcement. Small group helped interactive discussion with faculty. However, quiz, case based matching exercises and problem solving type of exercises made learning interesting.

Overall, the students opined that the workshop had not only increased their knowledge and understanding of chronic care for diabetes, but had empowered them with the necessary skills and confidence to tackle the patients with diabetes. Majority of the students wanted the workshop to be a part of their regular medical curriculum. 


\section{Conclusion}

Intensive Integrated workshop on chronic care of diabetes for medical students was very effective in increasing the knowledge and understanding of chronic care for diabetes. The students opined that the workshop was successful in imparting the essential skills and confidence for tackling the patients with diabetes. However, since this was an educational intervention study done on a small sample of students, experience from similar studies done on a larger number of students and from other medical institutions and or state universities would be requirement to validate the findings of this pilot study.

\section{Discussion}

Chronic diseases are a serious threat to health and longevity of human beings. India is noticing an increase in chronic non communicable diseases like diabetes, hypertension, coronary heart diseases, cancers etc ${ }^{[9,10]}$. It is estimated that the deaths and disabilities from chronic diseases will soon exceeds that from communicable disease. Many surveys are pointing to the fact that chronic disease risk factors are becoming increasingly common in India and are gravitating toward the urban poor ${ }^{[11]}$. As the number of persons with diabetes increases the number of people requiring chronic care increases. Majority of these patients receive the bulk of their medical care from general primary care, however, the economic burden of chronic disease like diabetes is still not well recognized ${ }^{[12]}$.. Moreover, the primary health care can play a strong role in chronic care of diabetic patients ${ }^{[13]}$. Unfortunately, the present primary health care system is weak and ill-equipped to provide the necessary chronic care for diabetes ${ }^{[14]}$.

Today Medical curriculum, teaching and learning are compartmentalized, with a lot of stress on knowledge oriented evaluation and very little stress on communication and supervision. The present focus of diseases centered care has to undergo a paradigm shift towards person centered care ${ }^{[15]}$. Serious research to devise a cost effective and feasible chronic care model for diabetes into the health care delivery system is the need of the hour ${ }^{[16]}$. Capacity building of the health staff in the form of medical students, resident doctors through intensive integrated training workshops could be a feasible, quick, effective and sustainable strategy for better quality chronic care of diabetes ${ }^{[17]}$.

\section{Acknowledgements}

The Registrar, Rajiv Gandhi University, The Director and Medical Superintendent, Staff of Department of General Medicine and Department of Community Medicine, Mandya Institute of Medical Sciences, Mandya. We also acknowledge the Karnataka Health Promotion Trust and St. John's medical College Faculty for all their help and support.

\section{Funding}

This program was a part of the pilot project on Continuum of Care for Chronic Common Conditions, funded by World Health Organization, SEARO India office. A part of the data pertaining to the chronic care of diabetes is presented here. The study was carried out as a multi-centric study in 5 medical colleges (affiliated to Rajiv Gandhi University of Health Sciences, Bangalore, Karnataka). St. John's Medical College and Karnataka Health Promotion Trust supported the project with technical support. The results of this study are exclusively from the study site MIMS, Mandya, Karnataka.

Ethical clearance: Obtained from the ethical committee.

Conflict of Interest: The authors declare no conflicts of interest. 


\section{REFERENCES}

1. National Diabetes fact sheet 2011. Fast facts on diabetes. Available at www.cdc.gov/diabetes/pubs/pdf/ndfs_2011.pdf accessed on Jan 3rd 2012at 11.03 am

2. Report of the Commission on Macroeconomics and health. Macroeconomics and Health: Investing in Health for Economic Development. World Health Organization; Geneva:2001.

3. Tackling NCDs: the capacity of countries to respond. Global status report on noncommunicable diseases 2010. World Health Organization. Available at http://www.who.int/nmh/publications/ncd report2010/en/index.html April 2011 accessed on Dec 17 2011 16:03 hrs.

4. Bodenheimer T, Wagner EH,Grumbach K. Improving primary care for patients with chronic illness. The Chronic care. Innovations in Primary Care. JAMA:2002;vol288;1775-9[PMID:12365965]

5. Bodenheimer T, Wagner EH,Grumbach K. Improving primary care for patients with chronic illness. The Chronic care Part II. Innovations in Primary Care. JAMA:2002;vol288;1909-14[PMID:12377092]

6. Reddy IKS, Shah B, Varghese C, Ramadoss A. Responding to the threat of chronic diseases in India. Lancet 2005; 366: 1744-9.

7. Innovative care for chronic condition: building blocks for action. Geneva: WHO; 2006. Available at: www.who.int/chronic_conditions/ icccreport/en/html

8. Abegunde $\mathrm{D}$, Mathers $\mathrm{C}$ et al.The burden and costs of chronic diseases in low-income and middle-income countries. Lancet ; 370: 2007:1929-1938.

9. Beaglehole R, Ibrahim S, Reddy S, et al., on behalf of the Chronic Disease Action Group. Prevention of chronic diseases: a call to action. Lancet; 2007: 370: 2152-2157.

10. Jordan EJE, Pruitt SD, Bengoa R, Wagner EH. Improving the quality of health care for chronic conditions. Developing Research and Practice. Qual Saf Health Care 2004;13:299-305. Available at www.sqhc.com

11. Wagner EH, Grothaus LC, Sandhu N, Galvin MS, Mc Gregor M, Artz K et al. Chronic Care Clinics for Diabetes in Primary Care-A system-wide randomized trial. Diabetes Care; 25(4): April 2001:695-700. Accessed on 1st November 2011 at 9 am at http://www.ncbi.nlm.nih.gov/pubmed/8941260

12. Gretchen AP, Trevor JO,Sharlene E,David S, Thomas JS, Maria MB et al. Translating the chronic care model into the community results from a RCT of a multifaceted diabetes care intervention. Diabetes Care. American Diabetes Association. Accessed at http://care.diabetesjournals.org/content/29/4/811 on Dec $28^{\text {th }} 2011$.

13. Marshall SJ. Developing countries face double burden of disease. Bull World Health Organ 2004; 82: 556-560.

14. Janssens B, Damme WV, Raleigh B, Gupta J, Khem S, Soy TK et al. Offering integrated care for HIV/AIDS, diabetes and hypertension within chronic disease clinics in Cambodia.MilbankQ. 1996;74(4):511-44.accessed on 31 stOct 2011 at $12 \mathrm{pm}$. http://www.cgdev.org/doc/expert\%20pages/nugent/Nugent_Annals_article.pdf

15. K Strong, C Mathers, S Leeder, $\mathrm{R}$ Beaglehole. Preventing chronic diseases: how many lives can we save? Lancet 2005; 366: 1578-82.

16. Lopez AD, Mathers CD, Ezzati M et al. Global Burden of Disease and Risk Factors. World Bank; Washington DC:2006.

17. Preventing Chronic Diseases: A Vital Investment.World Health Organization and the Public Health Agency of Canada. World health Organization; Geneva:2005. 